\title{
The Effect of Physical Factors on Fecal Coliform Viability Rate in Sewage Sludge
}

\author{
S. N. Al-Bahry'1, I. Y. Mahmoud ${ }^{2}$, S. K. Al-Musharafi ${ }^{3}$ \\ ${ }^{1}$ Department of Biology, College of Science, Sultan Qaboos University, Muscat, Oman \\ ${ }^{2}$ Department of Biological Sciences and Chemistry, University of Nizwa, Nizwa, Oman \\ ${ }^{3}$ Department of Applied Biotechnology, Sur College of Applied Sciences, Sur, Oman \\ Email: snbahry@squ.edu.om
}

Received December 2013

\begin{abstract}
Experiments were conducted on the survival rate of fecal coliform after spreading the sewage sludge for desiccation on sludge beds in an open field throughout the year. The ambient temperature, humidity, sunlight intensity and solar radiation were measured during the period of sludge desiccation. The maximum average temperature, sunlight intensity and solar radiation were recorded throughout the year. During May and August the minimum microbial counts were recorded after four weeks of sludge desiccation. Relative humidity did not have significant effect on survival rate. The minimum microbial counts were taken after four weeks of sludge drying. When the sludge was mixed with three different media, the maximum count of fecal coliform was presented when soil mixed with sludge and irrigated with treated sewage effluent (TSE). When soil mixed with sludge irrigated with well water, the number of fecal coliform count dropped significantly. The minimum count occurred when compost was used instead of sludge. This was a clear indication that the source of contamination was from sludge and was mostly contributed by the TSE irrigation. The use of dried sludge after four weeks of treatment had the lowest fecal coliform count and was safe to be used as fertilizer for farming. Oman is located in a semi-equatorial belt with arid environmental conditions which are ideal for elimination of microbial pathogens. Thus, sludge desiccation in such environmental conditions, specifically during the hot months of the year, is perfect for such practice.
\end{abstract}

\section{Keywords}

Sewage Sludge; Treated Sewage Effluent; Fecal Coliform; Viability Rate; Environmental Factors

\section{Introduction}

Oman is considered to be one of the most arid countries in the world with an annual rainfall approximately 80 $\mathrm{mm}$ (Kwarteng et al., 2009). With the rapid increase in the industrial and agricultural activities associated with the rapid increase in population, the demand for water is rapidly increasing, particularly during the last two decades. As a result, the desalination program associated with this condition is expanding rapidly throughout the country. There is also a rapid increase in the use of recycled water due to water shortage. The recycling water is 
used in agriculture and public parks (Al-Bahry et al., 2012a; Al-Musharafi et al., 2012). The number of sewage treatment plants (STPs) is increasing significantly in Muscat. Recently, the STP network is being constructed in Muscat, Oman covering most of the metropolitan sectors and the adjacent communities.

Sewage recycling is associated with the formation of sludge. Sludge is used either as fertilizer, incinerated or buried in landfills (Horsewell et al., 2007).

Disinfection using chlorine is a common practice before the release of treated sewage effluent (TSE). However, it was reported that microbial regrowth of multiple antibiotic resistant bacteria in biofilms of TSE distribution lines occurred as the effluent was pumped away at a distance from the source of disinfection (Al-Bahry et al., 2009). Also, it was reported the treated sewage effluents from the three sewage treatment plants (STP) contained multiple antibiotic resistant fecal coliform and Escherichia coli which contributed to soil contamination. Microbial counts increased significantly farther from the main TSE storage tank (Al-Bahry et al., 2012a). It was suggested that multiple antibiotic resistant bacteria from TSE can be used for biomonitoring environmental pollution (Al-Bahry et al., 2012b).

A fecal coliform, Escherichia coli, is a normal flora bacterium of animal digestive tract. It has been used as an indicator of fecal contamination of food and water and its existence indicates the possibility of digestive system microbial pathogens such as Salmonella, Shigella, and Vibrio spp contamination (Al-Bahry et al., 2012a).

Recently, rapid distribution of multiple antibiotic resistant microbes generates dangerous pathological conditions to human health, especially with the decline in finding new antibiotics. Recent increased use of antibiotics triggered simultaneous increase in contamination among domestic animals and humans by food and vegetables. The pathogens can easily contaminate soil and underground water.

The survival rate of microorganisms in the sewage sludge depends on temperature, moisture and the time of application to soil (Horsewell et al., 2007). In this study, the environmental conditions in Oman are ideal for eradication of pathogens, and consequently can be used as fertilizer. Lack of rainfall during most of the year, high temperature and long periods of intensive sunlight are ideal conditions to significantly reduce fecal coliform and pathogens.

The aim of this investigation is to study the survival rate of coliform as indicators for the possible existence of pathogen in the contaminated material.

\section{Materials and Methods}

The study area is located in Muscat, Oman. The sludge was taken from a residential area sewage treatment plant. Sludge was dried on dry beds in an open environment exposed to ambient temperature and relative humidity. The hours of sunlight and solar radiation (sunshine) were recorded using sunshine sensor (AT Delat, UK). The average environmental parameters were recorded weekly throughout the year.

Sludge, TSE, well water, soil and compost samples were collected throughout the year. All samples were collected aseptically during each week for fecal coliform counts following the standard methods (APHA, AWWA, WEF, 1998). The samples were stored immediately in a cool box and sent for analyses. Membrane filtration technique was used for the total fecal coliform count.

\section{Results}

There is a wide variation in temperature range between winter and summer. Temperature begins to rise in February, riches a peak in May through July, and then starts to drop gradually in August through December (Figure 1). Although the average is below $40^{\circ} \mathrm{C}$, maximum daily recorded temperature was $46.8^{\circ} \mathrm{C}$ in May and the minimum was $14^{\circ} \mathrm{C}$ in January (Figure 2).

Relative humidity is high during January through February, drops in May, then starts to rise in June through September, drops in October and begins to rise in November through December (Figure 3).

Sunlight intensity varies 8 - 10 hours daily during most of the year. Solar radiation, which follows the sunlight intensity period, has a similar pattern (Figure 4).

The survival rate of fecal coliform dropped significantly by the fourth week of each month. There is a minimal viability rate of coliform. Viability rate of coliform increased in the months December through April throughout the year for four weeks of each month. The maximum decrease of the fecal coliform viability was during May through August which correlated to the rise of temperature, sunlight intensity and solar radiation (Figure 5). 


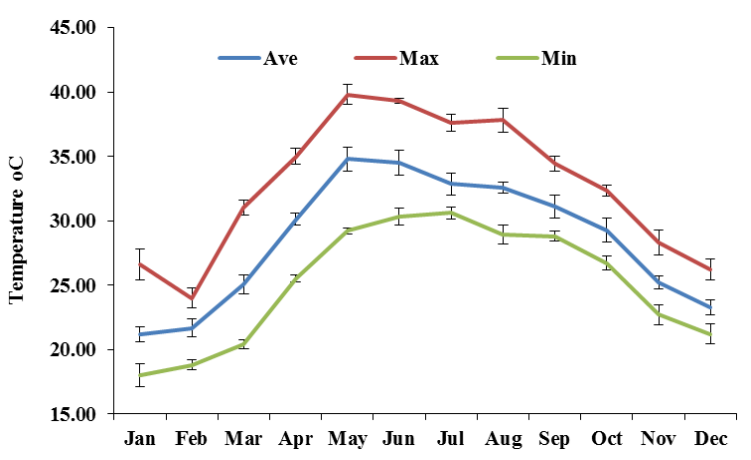

Figure 1. Annual Maximum, minimum and average temperature for Muscat, Oman.

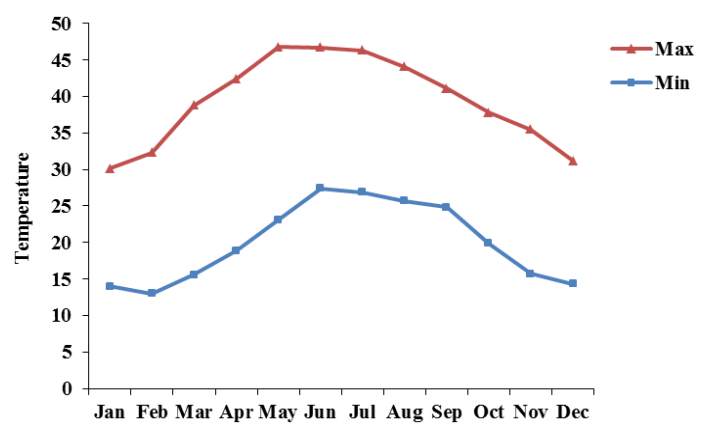

Figure 2. Maximum and minimum daily temperatures during month of the year.

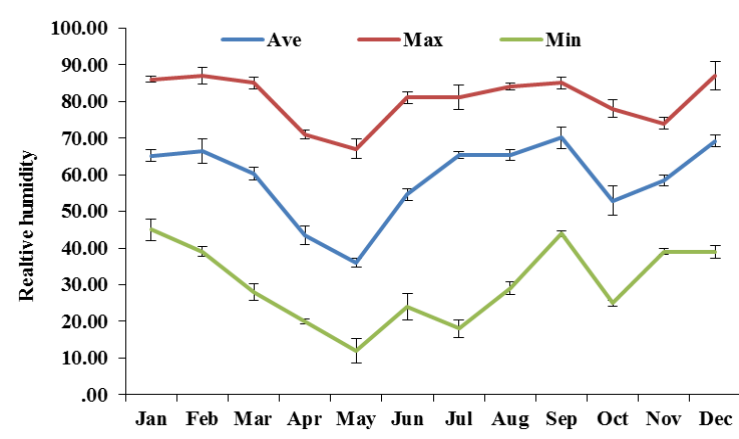

Figure 3. Maximum, minimum and average relative humidity for Muscat, Oman.

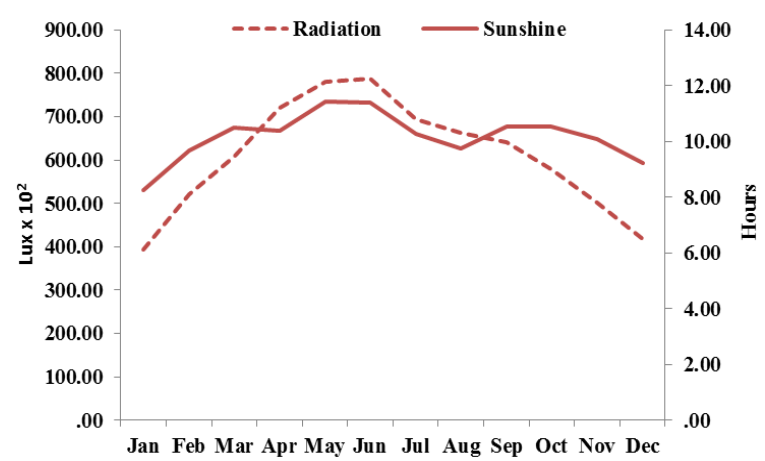

Figure 4. Sunlight hours and solar radiation variation throughout the year. 
The fecal coliform survival rate in the sludge is significantly low during May through July. Treated sewage effluent (TSE) did not significantly affect the fecal coliform survival rate in soil mixed with sludge and used as fertilizer. When the soil mixed sludge was irrigated with well water the fecal coliform count dropped significantly. The lowest fecal coliform counts were when compost was mixed with soil and irrigated with well water. The annual fecal coliform count in the four media was significantly higher in months of April and August than other months. This is correlated with optimal temperatures for growth of coliform. The optimal growth temperature of coliform is $35^{\circ} \mathrm{C}-37^{\circ} \mathrm{C}$ (Figures 1 and $\mathbf{6}$ ).

\section{Discussion}

The usage of wastewater in agriculture is a common practice especially when the water source is inadequate. When contaminated wastewater is used, it can cause major health problems. The survival rate of microorganisms is prolonged sunlight, high temperature and dry conditions reduce microbial viability. In some countries the sludge is first stabilized by anaerobic digestion which can eliminate some of the pathogens in the sludge. However, frequently the survival rate remains high and can be more harmful than beneficial, especially in the country with less, rainfall (Vassueur et al., 1996; Davis et al., 1999; Leclerc et al., 2001; Zaleski et al., 2005).

The ideal environmental factors for eliminating or reducing pathogens in the sludge requires high temperature, intensive sun light, and low relative humidity (Horswell et al., 2007). In Oman, these environmental factors exist during most of the year. Thus, using the sludge as fertilizer is beneficial for farming due to its richness in organic matter.

In addition, the extensive usage of TSE for agriculture and public parks was reported to contain microbial pathogens that may pose public health hazards (Al-Bahry et al.). Thus, eliminating the harmful microorganisms from the sludge by desiccation is crucial to the environment.

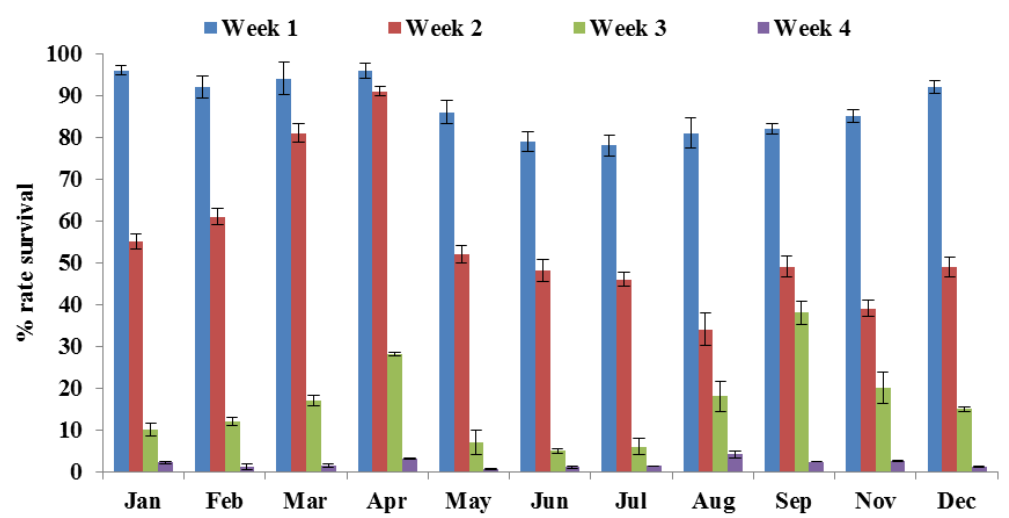

Figure 5. Monthly percentage of survival rate of fecal coliform throughout the year. There is a significant drop in survival rate between the first and the fourth week of each month except for March and April.

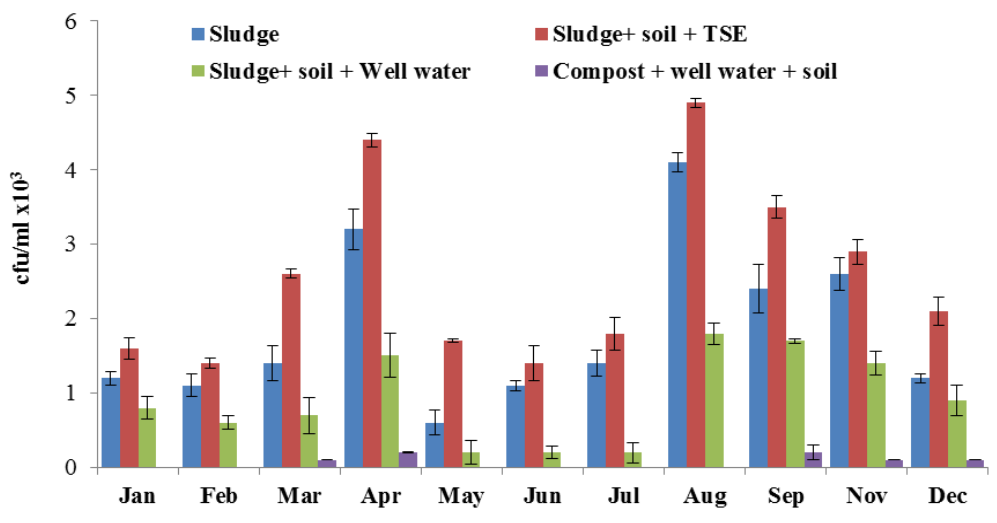

Figure 6. Effect of different media on the survival rate of coliform. 
Natural process of sludge desiccation has two beneficial environmental elements, reducing microbial pathogens from the environment and the benefit of using sludge as fertilizer. However, the use of desiccated sludge has some adverse environmental conditions such as accumulation of heavy metals in soil and its infiltration of underground water (Al-Musharafi et al., 2012, 2013a, 2013b). In addition, sludge may contain hydrocarbons, pesticides, antibiotic residuals and pharmaceuticals. Release of pharmaceuticals and antibiotic residuals through TSE or sludge to the environment is detrimental and leads to the emergence of antibiotic resistant microbes (Al-Bahry et al., 2009, 2012a, 2012b).

One way of eliminating this hazard condition is by spreading the sludge alternatively and rotationally in farming fields at distance from each other to prevent accumulation of pollutants specifically heavy metals. Also, the area where the sludge is applied must be tested periodically for the presence of heavy metals and other pollutants.

In conclusion, the presence of natural conditions in Oman, such as prolonged intensive sunlight, high temperatures and low relative humidity during most of the year, it would be useful environmental practice for eliminating pathogenic microorganisms from the sewage sludge in Oman.

\section{References}

Al-Bahry, S. N., Mahmoud, I. Y., \& Al-Musharafi, S. K. (2012a). Antibiotic Resistant Bacteria Used as Bioindicators of Environmental Pollution Produced by Tertiary Treated Sewage Effluent. 11th International Conference on Modelling, Monitoring and Management of Water Pollution. WIT Transactions on Ecology and the Environment (pp 313-321). New Forest.

Al-Bahry, S. N., Al-Zadjali, M. A., Mahmoud, I. Y., \& Elshafie, A. E. (2012b). Biomonitoring Marine Habitats in Reference to Antibiotic Resistant Bacteria and Ampicillin Resistance Determinants from Oviductal Fluid of the Nesting Green Sea Turtle, Chelonia mydas. Chemosphere, 87, 1308-1315. http://dx.doi.org/10.1016/j.chemosphere.2012.01.051

Al-Bahry, S. N., Mahmoud, I. Y., Al-Khaifi, A., Elshafie, A. E., \& Al-Harthy, A. (2009). Viability of Multiple Antibiotic Resistant Bacteria in Distribution Lines of Treated Sewage Effluent Used for Irrigation. Water Science \& Technology, 60, 2939-2948. http://dx.doi.org/10.2166/wst.2009.687

Al-Musharafi, S. K., Mahmoud, I. Y., \& Al-Bahry, S. N. (2013a). Heavy Metal Pollution from Treated Sewage Effluent. APCBEE Procedia, 5, 344-348. http://dx.doi.org/10.1016/j.apcbee.2013.05.059

Al-Musharafi, S. K., Mahmoud, I. Y., \& Al-Bahry, S. N. (2013b). Heavy Metals Infiltration from Sewage Treated Effluent into Soil and Tomato Plants. IPCBEE, 50, 16-25.

Al-Musharafi, S. K., Mahmoud, I. Y., \& Al-Bahry, S. N. (2012). Heavy Metal Contamination from Treated Sewage Effluents. 11th International Conference on Modelling, Monitoring and Management of Water Pollution. WIT Transactions on Ecology and The Environment (pp381-389). New Forest.

APHA/AWWA/WEF (American Public Health Association/American Water Works Association/Water Environment Federation (1998). Standard Methods for the Examination of Water and Wastewater (20th ed.). Washington DC: American Public Health Association/American Water Works Association/Water Environment Federation. Baltimore: United Book Press Inc.

Horswell, J., Ambrose, V., Clucas, L., Leckie, A., Clinton, P., \& Speir, T. W. (2007). Survival of Escherichia coli and Salmonella spp. after Application of Sewage Sludge to a Pinus Radiata Forest. Journal of Applied Microbiology, 103, 13211331. http://dx.doi.org/10.1111/j.1365-2672.2007.03373.x

Kwarteng, A., Dorvlo, A. S., \& Kumar, G. T. (2009). Analysis of a 27-Year Rainfall Data (1977-2003) in the Sultanate of Oman. International Journal of Climatology, 29, 605-617. http://dx.doi.org/10.1002/joc.1727 